\title{
Systemic Challenges Facing Public Procurement Policy Development in Tanzania: An Institutional Analysis
}

\author{
Bakari Maligwa Mohamed \\ Lecturer in Procurement and Supply Chain Management, School of Business \\ Mzumbe University,P’O Box 6, Mzumbe, Tanzania \\ Email: bmmohamed@mzumbe.ac.tz
}

Received: February 27, 2017 Accepted: March 14, 2017 Published: April 05, 2017

doi:10.5296/jpag.v7i1.10939 URL: http://dx.doi.org/10.5296/jpag.v7i1. 10939

\begin{abstract}
Public procurement policy is vital for effective, efficient, economic, and transparent functioning of the public procurement system. Policy development is a political decision making platform. This paper tries to do an institutional analysis dwelling on the identification of the relevant systemic challenges and the related issues facing public procurement policy development in Tanzania. The paper utilises institutional and Delphi policy analyses to analyse systemic challenges facing public procurement policy development. Data for this paper were collected through Delphi in-depth interviews and documentary reviews and analysis. Data analysis were done by thematic and Delphi policy analyses. Analyses of data and evidences show that, Tanzania has been evidenced to have no public procurement policy. The public procurement policy development process has been halted for at least four years since 2012 due systemic challenges. The identified and analysed relevant systemic challenges facing public procurement policy development, inter alia, were: neglected politics and lack of political willingness; unrealistic policy process model; failure to achieve the desired qualities of policy development and difficult in achieving the policy qualities and therefore failure to make progress; and incoherent and incomplete institutional and structural changes that led to the emergence of new institutional and structural challenges.
\end{abstract}

Keywords: Tanzania, procurement policy, policy process, policy paper, systemic challenges 


\section{Introduction}

Public procurement is a policy tool (Caravella, 2009) and is associated with business (Wittig, 1999). That is, the acquisition of goods and services on the best possible terms is a business phenomenon. As a known phenomenon, public procurement has broader social, economic and political implications (Caravella, 2009). Essentially therefore, public procurement can only be appropriately addressed through a public procurement policy (United Republic of Tanzania (URT), National Public Procurement Policy - NPPP, 2012 draft). Unfortunately, as underscored in the NPPP (2012 draft) that, "Reforms on the Tanzania public procurement system have not been as focused as intended. In policy formulation perspectives, it would have been more prudent to have developed a public procurement policy before thinking of the public procurement legislation. The procurement legislation would have been a derivative of the public procurement policy instrument." In principle, and as accepted in the policy formulation mechanism; the formulation of a public procurement policy is considered as a first step in the establishment of an effective public procurement system (URT, NPPP, 2012 draft). Tanzania has had not considered this policy development and implementation fact. Instead, Tanzania had ventured into enacting public procurement principal legislation (Chapter 410) instead of first developing public procurement policy framework. This was a noticeable gap since the introduction of the Public Procurement Act - PPA, No. 3 of 2001. The gap was inherent whilst enacting the PPA No. 21 of 2004, the PPA No. 7 of 2011, and the PPA (Amendments) No. 5 of 2016 respectively.

The enactment of the unified public procurement legislation in 2001 was made compliant with the proposed institutionalised public procurement systems as per the requirements of the United Nations Commission on International Trade and Law (UNCITRAL) Procurement Modal Law 1994, the World Bank (WB), the donor agencies, and development partners (URT, 2003 and 2007). Public procurement legal, institutional and systemic reforms were needed to harmonise the United Nations member countries public procurement systems. Therefore, Tanzania was made to comply with the UNCITRAL Procurement Modal Law (1994), donor countries, and development partners. That was the essence of institutionalised systemic reforms in line with the procurement modal law (UNCITRAL, 1999).

One of the fundamental systemic reform requirements the envisaged reforms were presupposed to capture was the need to involve the people in all spheres of political, economic, social, technological, environmental, legal, and their socio-economic development agenda (URT, NPPP, 2012 draft). This, as a socio-political priority, was the urge of decentralisation by devolution - the D-by-D. Whereby, the people were and are still considered as the owners of the [socio-political development] systemic reforms (see Local Government Capital Development Grant [LGCDG] System: Legislation, Roles and Responsibilities for Local Governments, Prime Minister's Office Regional Administration and Local Government, PMO-RALG, Dodoma, 2006). The developments in the public procurement regulatory and institutional frameworks between 1992 and 2007 as recommended by the Crown Agents (URT, 1992) and the Country Procurement Assessment Report - CPAR (URT, 1996 and 2003) were, inter alia, the enactment and commissioning of the PPA No. 3 of 2001 and later the PPA No. 21 of 2004 (URT, 2007). The public 
procurement laws were made in order to streamline and institutionalise public procurement system in Tanzania. Primarily, the enactment of PPA No. 21 of 2004 and the establishment of the Public Procurement Regulatory Authority (PPRA) replacing the Central Tender Board (CTB) have had made significant strides in the public procurement regulatory and institutional frameworks. The PPRA had been given more functional mandate and institutional powers to ensure that regulatory and institutional frameworks within the institutionalised public procurement system are compliant with the public procurement legislation (URT, 2007).

In the public policy development circles, systemic challenges are usually issues found within and across the micro-mezzo-macro institutional levels in the policy development framework. These systemic issues are either found within or without the political decision making system. As a known phenomenon, the public policy development process is found within the political system. Therefore, systemic challenges around the public policy development process and activities related thereto are inevitable. In this context, whenever systemic challenges are mentioned, the contextual meaning should be taken as critical issues within and without the public policy development process that influence the public policy development institutional performance in deliverance of public policy.

This study was focused on identifying and analysing systemic challenges facing public procurement policy development in Tanzania. Tanzania has no national public procurement policy framework (URT, 1992; URT, 1996; URT, 2003; URT, 2007; URT, NPPP, 2012 draft). Therefore, the envisioned systemic challenges and inherent systemic issues facing public procurement policy development in the micro-mezzo-macro institutional levels in the Tanzania public policy development framework, need institutional analysis to dwell on: highlighting the basic characteristics of the Tanzania public policy development framework; identifying relevant systemic challenges and issues related thereto facing public procurement policy development; using the Delphi policy analysis to analyse the identified systemic challenges and issues facing public procurement policy development process; and critically analysing how sound public procurement policy could be useful for effective, efficient, economic and transparent public procurement regulatory and institutional frameworks in ensuring effective, efficient and economic performance of the Tanzania public procurement system.

\section{Theoretical Debate}

Public policy development process is an activity within a political system. The process is usually executed by institutions within the political decision making perimeter. Therefore, in analysing systemic challenges facing public procurement policy development process, two theories need to be considered for this academic paper. These theories are, inter alia: Institutional Theory (Scott, 2004); and Political Systems Theory (Easton, 1957). Through institutional analysis in a political system is where systemic challenges influencing public procurement policy development process can be studied and comprehended. This paper, as a matter of theoretical stand, has been focussed on the political institutionalism. Thus, institutional and political systems theories are hereby adopted. 


\subsection{Institutional Theory}

Institutional theory is thought to be the traditional approach in examining the elements of public procurement (Obanda, 2010; Tukamuhabwa, 2012). Public procurement policy is the precursor of an effective, efficient, economic, and transparent public procurement system. Therefore, institutions envisaged to be working in the processes and activities for developing and implementing the public procurement policy should have been designed and structured within political institutionalism.

In public policy formulation and implementation, institutions are working within an integrative and interactive political system. Usually institutions are made to comply with the three Scott's pillars, namely: regulatory; normative; and cultural-cognitive (Scott, 2004). That, the regulatory pillar emphasises the use of laws, rules and sanctions as enforcement mechanism, with expedience as means for compliance; where, the normative pillar refers to the norms and values with social obligation as the basis of compliance. The cultural cognitive pillar rests on the shared understanding (common values and beliefs). From this theory, as adopted in the public policy development, all public institutions in the micro-mezzo-macro institutional levels working within the institutionalised public policy development system in Tanzania should be governed by the adopted public policy development norms within an existing political system.

The institutional pillars further identify organisational culture, social influence, organisational incentives and enforcement which are the prerequisites of compliance with procurement law and procedures (Scott, 2004). The normative and cultural pillars on the other hand, are reflected through the organisational structures and cultures. Institutions consist of cognitive, normative, and regulative structures and activities that provide stability and meaning to social behaviour. Institutions are transported by various carriers (cultures, structures, and routines) and they operate at multiple levels of jurisdiction (Scott, 2004). These elements are the building blocks of institutional structures, and provide the concept of institutions. Institutions are everywhere, governing our lives in fundamental ways (Polski and Ostrom, 1999). The three pillars of institutions would serve as the analytical framework for considering the key actors and institutions involved in the public procurement policy development process.

\subsection{Political Systems Theory}

The political system comprises those identifiable and interrelated institutions and activities in a society that make authoritative allocations of values (decisions) that are binding on [the] society (Easton, 1957 and 1965). In considering the Political Systems Theory (Easton, 1957 and 1965), it is inevitable for the public procurement system to work outside the political system (see Wittig, 1999 and 2007; Watermayer, 2011). The Easton (1957) political system model (vide Figure 2.1) briefly explains:

Demands are the claims for action that individuals and groups make to satisfy their interests and values. Support is rendered when groups and individuals abide by election results, pay taxes [taxpayers], obey laws, and otherwise accept the decisions and actions undertaken by the political system in response to demands. The amount of support for a political system 
indicates the extent to which it is regarded as legitimate, or as authoritative and binding on its citizens [taxpayers]. Outputs of the political system include laws, rules, judicial decisions, and the like (Easton, 1957; with annotations and emphasis).

Figure 2.1: The political system in the input-process-output model

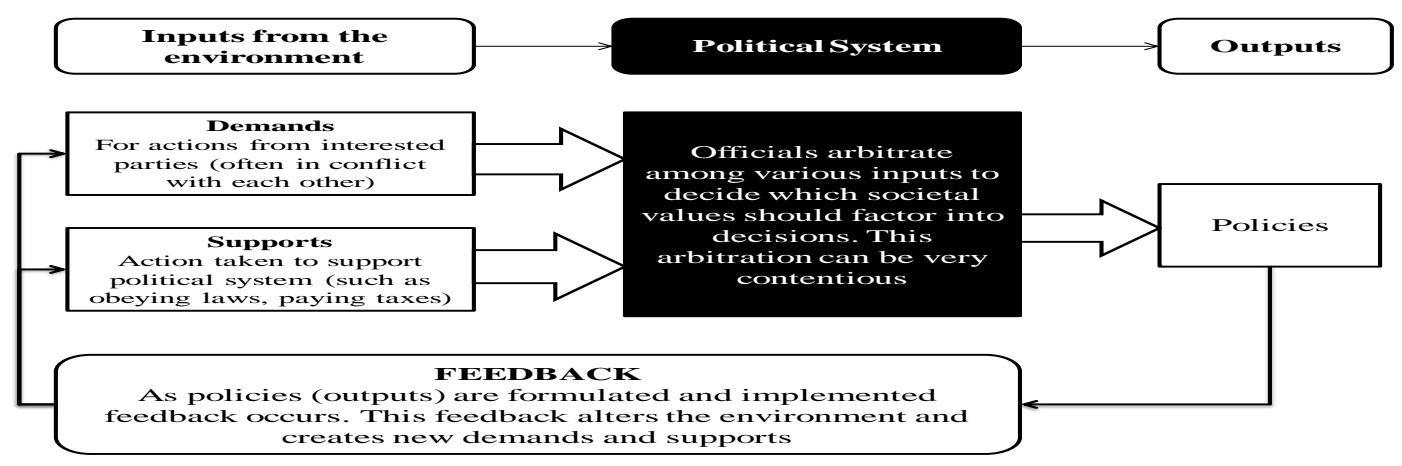

Source: Slightly adapted and modified from Easton (1957)

This model is the most useful in understanding policy-making, as it gives us a good picture of how the separate components interact in the policy-making process and highlights how this interaction can be full of conflicts (see Caravella, 2009). It can be applied in nearly all types of political and policy-making situations (see Easton, 1965). Political institutionalism has become more historical and focused on historical processes, and focuses theoretical attention on the interaction of actors at a medium-systemic, inter-organizational, or mezzo level. These actors are seen as working within institutional constraints, as well as with constraints on resources and other means of action, and attempting to influence state policy. Changes in state policies in turn set processes in motion that influence the interests and strategies of actors that will determine whether programs will feed back in a way that strengthens the program or undermines it or leaves it open to changes at a later time. The main theoretical framework is that macro level political institutions shape politics and political actors, who act under constraints that may influence their impact on states and policies, refashioning political institutions in the process (Amenta and Ramsey, 2010).

\section{Research Methodology}

This study needed both, primary and secondary data. Being an institutional analysis, secondary data were considered as primary in the context of their contents whenever they form the bases for analysis in meeting the specific research objectives. Essentially, primary data from primary sources on the existence of systemic challenges were collected in justifying their existence and influences. Specific research objectives were and still are:

1. To alienate the basic characteristics of the Tanzania public policy development process within the macro-mezzo-micro institutional levels;

2. To identify relevant systemic challenges and issues related thereto facing the Tanzania public procurement policy development process; 


\section{$\Lambda$ Macrothink}

3. To use the Delphi policy analysis to analyse the identified systemic challenges and issues facing the Tanzania public procurement policy development process; and

4. To critically analyse how sound public procurement policy could be useful for effective, efficient, and economic regulatory and institutional public procurement framework.

\subsection{Methods of Data Collection}

\subsubsection{Data Mining}

Data mining was the source of secondary data (and sometimes information). Data mining is a practical topic and involves learning in a practical, not a theoretical sense (Witten and Frank, 2005). Data mining as in Witten and Frank (2005) was used to dig deep into the available and accessible data on the systemic challenges from both primary and secondary data sources within and across the micro-mezzo-macro institutional levels in the Tanzania public policy development framework.

\subsubsection{Documentary Sources}

Documentary and archival reviews and analysis were very essential for secondary data collection. Therefore, content analysis, as a qualitative approach of getting the content of data in the form of ideas and propositions through various documents used in an organisation (Krishnaswamy et al., 2009) was applied. Thus, available and accessible (open to the public) documents from the mezzo and macro institutional levels in the public policy development institutions relating to the topic of analysis were reviewed and analysed. These documents include, but not limited to, published and unpublished policy and regulatory documents, published and unpublished audit and performance evaluation reports, investigative reports, official magazines, official gazettes, professional journals, and other related and relevant reports.

\subsubsection{Specialised Delphi In-depth Interviews}

Specialised Delphi in-depth interviews were conducted with the purposively selected ten $(\mathrm{N}=10)$ case respondents from the micro, mezzo and macro policy development institutional levels in the Tanzania public policy development framework. Specialised in-depth interviews involved talks with senior public officials, experts and professionals who have enough expertise and are familiar with the envisaged systemic challenges and issues related thereto on the public procurement policy development within the policy, regulatory, and the allied institutions. Specialised Delphi interviews were done through the help of the Delphi in-depth interviewing protocol. The Delphi technique is a widely used and accepted method for gathering data from respondents within their domain of expertise (Hsu and Sandford, 2007). This technique is designed and used as a group communication process which aims at achieving a convergence of opinion on a specific real-world issue. The Delphi process, according to Hsu and Sandford (2007), has been used in various fields of study such as programme planning, needs assessment, policy determination, and resource utilization to develop a full range of alternatives, explore or expose underlying assumptions, as well as 
correlate judgments on a topic spanning a wide range of disciplines.

In-depth interviews with experts have been used with great success as an alternative to questionnaires (Gordon, 2008). In this study, senior public officials, professionals, and experts in the Tanzania public policy development framework who are working within the policy, regulatory and allied institutions within and across the macro, mezzo and micro institutional arrangements were first identified, invited to participate, and assured of their anonymity. However, and in most instances, they were not promised a report (feedback) based on the interviews. Appointments were made at the convenience of the interviewees. The Delphi in-depth interview protocol was prepared and tested to elicit judgments. According to Gordon (2008) feedback can be introduced if two or more rounds of interviews are employed. However, this study has only used single-round Delphi in-depth interview as agreed by Gordon (2008). Furthermore, this exercise was not designed to be statistically significant but rather to elicit ideas that can be important to subsequent analysis. Therefore, there was no need to presenting to case respondents information about emerging consensual issues derived from the interviews. Delphi (or expert) in-depth interviews, as in this institutional analysis, were an excellent means of obtaining such ideas.

\subsubsection{Data Analysis}

Qualitative data analysis was used. Data analysis was done by thematic analysis, institutional analysis, Delphi policy analysis, context and content analysis for qualitative data. Primarily, data analysis adhered to the institutional, context and content analysis of the systemic challenges and related issues thereto in line with the specific research objectives in attempting to meet the general research agenda. Ritchie and Lewis (2003) argue that qualitative content analysis involves a process designed to condense raw data into categories or themes based on valid inference and interpretation. The basic problem of content analysis, as thought and to be dealt with as contended by Jahoda (1958); is a conscious or unconscious process of observing and reporting only facts that fit some preconceived idea/ideas.

\section{Results, Findings and Discussion}

Here, this paper presents the results, findings and discussion based on the thematic categories, themes, sub-themes and issues derived from the specific objectives guiding the writing of this research paper. Thematic categories, themes, sub-themes and issues have been derived from the theoretical debate in line with the specific study objectives.

\subsection{Characteristics of the Tanzania Public Policy Development Process}

Policy development process in Tanzania is a political process. The micro-mezzo-macro policy development institutional levels (see Table 4.1) are within the Tanzania political system where political elites and cadres influence the decision making processes and activities therein. Policy development process - however political it is - should be based on the four major strands as enunciated in the Hallsworth, Parker and Rutter (2011). These strands, inter alia, are: Process: the actions recommended to produce policy; Qualities: the way in which these actions should be carried out; Structures: the institutional arrangements to support better policy making; and Politics: the way in which political aims and desires contribute to policy 
making.

In Tanzania, public policy development is a professional and technical process enshrined in the political system. The politics of the day has very many influences on the problem identification, agenda setting, policy development and approval, policy implementation and evaluation. The policy development process (see Table 4.1) in Tanzania is clearly summarized in Mattee (2007), that:

In principle, policies are usually proposed as a response to addressing and overcoming identified problems. The whole purpose is to try and ensure that root causes of the problem are identified and subsequently addressed in the design of policy. Generally, ideas may originate from individuals, communities, organisations, public or private institutions and other interest groups. These ideas are then worked up to become policies. The policy development process in Tanzania is supposed to use a bottom-up approach and to be participatory and consultative so as to ensure that people's views are accommodated. The process starts with recognition of a problem that needs to be solved. Having identified a problem what follows is identification of stakeholders upon who this problem impacts the most, and the roles of different stakeholders in addressing the problem and reaching a solution. All key stakeholders i.e. government and its institutions as well as key actors in the regions, the Local Government Authorities (LGAs) and local communities have the right to take part in the process. Stakeholders participation is advocated right from the early stages of the exercise to make sure ideas are shared and supported by all stakeholders. Participation may be effected through various methods including interviews and dialogue with various people (individuals or groups), workshops and round table meetings. The mass media may also be closely involved through publishing special articles and features in the newspapers, discussion in the radio and television programmes. The participatory approach is advocated in order to ensure policy papers are comprehensive, relevant and addressing stakeholders' views.

Table 4.1: Policy development institutional levels

\begin{tabular}{|l|l|l|}
\hline $\begin{array}{l}\text { Institutional } \\
\text { Policy Level }\end{array}$ & Policy Development Institutions & Institutional Role \\
\hline Macro & Parliament & $\begin{array}{l}\text { Comment on the } \\
\text { developed policy } \\
\text { Enact and/or amend } \\
\text { the law(s) to } \\
\text { implement the policy }\end{array}$ \\
\hline & Cabinet & $\begin{array}{l}\text { The principal } \\
\text { decision maker }\end{array}$ \\
& & \begin{tabular}{l} 
Discuss the policy \\
\hline
\end{tabular}
\end{tabular}




\begin{tabular}{|c|c|c|}
\hline $\begin{array}{l}\text { Institutional } \\
\text { Policy Level }\end{array}$ & Policy Development Institutions & Institutional Role \\
\hline \multirow{5}{*}{ Mezzo } & & $\begin{array}{ll}\text { paper submitted by } \\
\text { sector ministry }\end{array}$ \\
\hline & $\begin{array}{l}\text { Inter-Ministerial } \quad \text { Technical } \\
\text { (IMTC) }\end{array}$ & $\begin{array}{l}\text { - To ensure that the } \\
\text { proposed policy is in } \\
\text { harmony and/or in } \\
\text { conformance with } \\
\text { other sector policies }\end{array}$ \\
\hline & Cabinet Secretariat & $\begin{array}{l}\text { - In-depth discussion } \\
\text { on the proposed } \\
\text { policy to ensure it } \\
\text { addresses the } \\
\text { identified problem(s) }\end{array}$ \\
\hline & & $\begin{array}{l}\text { Determining the } \\
\text { rationality and } \\
\text { significance of the } \\
\text { proposed policy }\end{array}$ \\
\hline & Respective Ministry & $\begin{array}{l}\text { - } \begin{array}{l}\text { Setting policy } \\
\text { agenda }\end{array} \\
\text { - } \begin{array}{l}\text { Formulates proposed } \\
\text { sector policy }\end{array}\end{array}$ \\
\hline Micro & $\begin{array}{l}\text { Ministerial Departments and Agencies } \\
\text { (MDAs), Regions, Districts and Local } \\
\text { Government Authorities (LGAs), Academic } \\
\text { Institutions, Public Bodies, Private Sector, } \\
\text { Non-Governmental Organisations (NGOs), } \\
\text { Community Based Organisations (CBOs), } \\
\text { etc. }\end{array}$ & 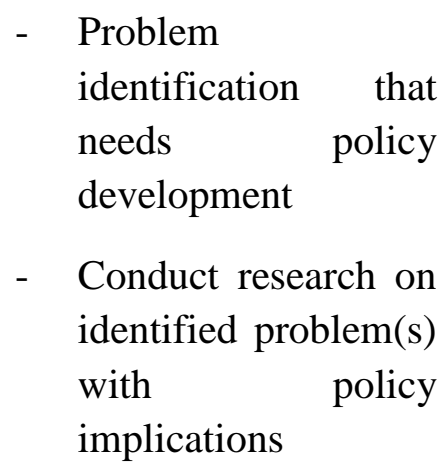 \\
\hline
\end{tabular}


In the micro-mezzo-macro institutional policy development levels, Tanzania policy development process captures, inter alia, various policy development institutions and/or organs within the political decision making spectrum. At the micro institutional policy level there are the Ministerial Departments and Agencies (MDAs), regions, districts and Local Government Authorities (LGAs), academic institutions, public bodies, private sector, Non-Government Organisations (NGOs), Community Based Organisations (CBOs), and other sector stakeholders.

The institutional role at the micro institutional level is to identify problems that need and/or require policy development. In the mezzo institutional policy level, as a matter of policy development process, we have the respective sector ministry, cabinet secretariat, Inter-Ministerial Technical Committee (IMTC), and the cabinet. The institutional role at the mezzo level in policy development is hinged on ensuring that the policy agenda is set, policy paper developed, the proposed is discussed and policy is approved, and policy is set to be tabled before the Parliament for comments and enacting and/or amending the laws to implement the developed policies (see Table 4.1). However, the policy development institutional levels (as in Table 4.1) are bureaucratic in nature. Their functioning always, despite of their establishments and institutional powers, is influenced by the political system and the governing philosophy of the ruling political elites. Nevertheless, in an effective policy development process and activities thereto, the political elites should effectively and efficiently use professionalism in the policy development endeavours. Otherwise there are going to be irrational bureaucracies that usually impede and halt the policy process.

\subsection{Systemic Challenges on the Tanzania Public Procurement Policy Development}

Due to the nature and complexity of the policy development process in a political decision making spectrum, inherent systemic challenges within and across the policy process are inevitable. Review of relevant literature (secondary data sources) and the Delphi in-depth interviews conducted for this study revealed that public procurement policy development process in Tanzania is faced by the following systemic challenges and issues related thereto: neglected politics (of the day) and lack of political willingness amongst the political elites and cadres; unrealistic policy process model; failure to achieve the desired qualities of policy development; and difficult in achieving the policy qualities. Therefore failure to make progress; and Incoherent and incomplete institutional and structural changes that led to the emergence of new institutional and structural challenges.

From the four enunciated systemic challenges and issues related thereto, this paper has singled out four thematic issues to be described, elucidated and discussed in order to meet the specific objectives of the paper. The thematic categories are: 1) Politics and political willingness; 2) Policy process model; 3) Qualities of policy development; and 4) Institutional and structural changes. Descriptions and discussion on these thematic categories, themes, sub-themes and related issues thereto are based on the evidences obtained from the qualitative data sources. Here, there is no distinction between data presentation, data analysis and discussion. This is due to the fact that in qualitative study, qualitative data collection is usually dependent on interpretation (Alhojailan, 2012). Therefore, there is no distinction 
between data collection and its analysis in qualitative research (Cassell and Symon, 1994).

\subsubsection{Politics and Political Willingness}

It is a known phenomenon that public policy development process is highly influenced by the political system (of the day). This known fact for the public policy development is also true for the public procurement policy development. As a policy tool (Caravella, 2009); public procurement system is also influenced by the political system. The political system comprises those identifiable and interrelated institutions and activities in a society that make authoritative allocations of values (decisions) that are binding on society (Easton, 1957 and 1965). In considering the Political Systems Theory (Easton, 1957 and 1965), it is inevitable for the public procurement system to work outside the political system (see Wittig, 1999 and 2007; Watermayer, 2011). Decision makers in the Tanzania political system have been neglecting the politics of the day and therefore rendered the public procurement policy development process in a halt. The procurement policy development process has been halted within and across the mezzo institutional policy levels for almost four years since 2012. One senior public official in the macro institutional policy level has said:

Changes occurring in the political system and the public governance have positive and negative impacts in the public procurement policy development process. Whenever there are shifts in the political system and the governance of the public sector management system there are some deliberate neglect on the previous policy decisions. The drive to have public procurement policy framework was initiated in the Fourth Phase Government (2005 to 2015). However, the Fifth Phase Government (2015 to 2020) has come with legislative amendments on the principal legislation (Chapter 410) in June 2016 instead of prioritising on the continued public procurement policy development process that was halted since the year 2013.

This observation shows a deliberate neglect on the politics of day and lack of political willingness to orthogonally deal with the public procurement policy development process in ensuring that Tanzania has public procurement policy framework. It is evidenced that, the politics of the envisaged political system and the governance of the public sector procurements are highly machinated and influenced by the political class decisions within the macro and mezzo policy institutional levels (the Cabinet and the Parliament). This happens regardless of who are the beneficiaries of the derailed efforts of the other in the leadership succession from one phase to the next in the same political landscape. Whenever there are changes in the political ideas in the political system [decision making machinery], there are changes in the previous political decisions on policy development processes and activities associated therein.

\subsubsection{Policy Process Model}

All ( $\mathrm{N}=10)$ Delphi in-depth interviewees, on their own terms thought that: policy development process cycles should produce policies that use government resources effectively and efficiently. However, almost every interviewee argued that they were divorced from reality. Arguably, policies are not made within the policy development process cycles. 


\section{Macrothink}

That, they added, policy development process is not how the real world works. There is a mismatch between the real world policy development process cycles and the actual policy development process cycles. Five interviewees in the mezzo and macro policy development levels have observed that: Tanzania public policy development process is obliged to represent the modernised policy development process. However, using the policy development model by showing and adhering to the sequential activities organised in a cycle has its challenges. Experienced policy makers are reacting against such a model - as the model does not accurately reflect the realities of policy making in the Tanzania policy development context. Policy development theories are not as the policy development practices in the real world.

If Tanzania public policy development institutions could have followed the public policy development model, Tanzania would have her national public procurement policy framework before the end of the $4^{\text {th }}$ Phase Government. However, the real world has been different from the theoretical world. The policy process model has not been fully followed in ensuring that Tanzania has her public procurement policy framework before the end of 2015. To date, Tanzania has got none of the public procurement policy framework save for procurement legal framework.

\subsubsection{Qualities of Policy Development}

Policy development should have clearly defined the desired qualities of the required policy. All $(\mathrm{N}=10)$ of the Delphi in-depth interviewees have observed that, Tanzania public procurement policy development process has failed to achieve the desired qualities of the public procurement policy development. The failure to achieve the envisaged policy qualities has led to the failure to make progress on the public procurement policy development process. One interviewee, who is an expert in the policy development process, has observed that:

The main thrust of the Public Procurement Policy Division (PPPD) in the Ministry of Finance and Planning is to define the qualities that public procurement policy development should possess. However, there is a failure on the micro and mezzo institutional policy levels to execute this function due to structural and institutional designs and fragmentation between the key institutions in the micro and mezzo institutional policy development levels. The defined policy qualities presented were supposed to be a series of high level features that could have produced effective public procurement policies. However, there were illogic policy features, institutional misunderstandings and irrational bureaucracies within and across the micro and mezzo institutional levels on the policy qualities of the required public procurement policy development process and the results thereto.

The failure of the policy division to spearhead the process and the progression of the public procurement policy paper within the micro institutional policy level and within and across the mezzo institutional policy level, and towards the completion of the policy development process has been halted due to ill-defined, unstructured, and unqualified policy development process and activities thereto. The proposed policy paper has been kept in the mezzo institutional policy level due to lack of political willingness of the decision makers in the political system. Some of the members and/or cadres in the political class within the decision making machinery are not well informed on the essence of the public procurement policy in 
accomplishing the Millennium Challenge Goals (MDGs) and therefore meeting the Tanzania Development Vision (TDV) 2025. Some politicians do not recognise that, "public procurement is the facilitator of socio-economic development." Therefore having national public procurement policy framework is essential in facilitating the effective, efficient, economic, and transparent public sector procurements - the essence of value for money which would add value into the socio-economic development equation through balancing the inputs and outputs in the economic development inputs-process-outputs model.

\subsubsection{Institutional and Structural Changes}

The enacted Public Procurement Act No. 3 in 2001 and Public Procurement Act No. 21 in 2004 respectively had had no provisions for the establishment of the policy division. Whereas, the Public Procurement Act No. 7 of 2011, inter alia, has established the Public Procurement Policy Division (PPPD) within the Ministry of Finance and Planning. The policy division was and still is mandated to use its institutional powers to deal with public procurement policy development. Despite this fact, the office of the PPPD was officially established before the enactment of the Act No. 7 of 2011. Objectively, the PPPD has tried hard to shoulder its institutional mandate. It enabled to issue the first draft (as a zero draft policy paper) of the National Public Procurement Policy (NPPP) in September 2012. Despite this recognised initiative, there are some cognitive institutional and structural challenges that were and still are hindrance toward accomplishment of the envisaged policy paper through the mezzo to the macro institutional policy development levels. The policy paper (first draft NPPP) has been put into a deliberate halt. There is no progress whatsoever. One expert in the macro institutional policy level has said that:

Whenever there are conflicting institutional and structural mandates between institutions within the same institutional level dealing with the same policy issues, conflicts are inevitable. These conflicts could be legal establishments, institutional mandates and powers, institutional independence, and where do each institution report within the macro-mezzo-micro institutional levels. Whenever there imbalance of institutional mandate and powers between the institutions, the policy development process shall always come to a halt.

In order to extricate the public policy development institutions within and across the micro and mezzo institutional policy levels from shackles of irrational bureaucracies, there should be clear separations of mandates and institutional powers for each. Whereupon, each institution in the public policy development cycle should be required to have clear sets of the defined policy qualities. The policy development path should be made to show what each institution should do, how they should do it, and when they should accomplish each step in the policy process cycles. The qualities of the policy process should be made clear and succinctly defined. Currently, the designs and structures of the public policy development institutions are incoherent, incomplete with inadequate institutional mandates.

\subsection{Procurement Policy Effectiveness on Institutional and Regulatory Frameworks}

Effectiveness of public procurement policy on regulatory and institutional frameworks depends on whether the approved policy addresses the identified policy problems in the 
public sector procurement system. There must be a unified legal framework that captures the policy agenda and related issues thereto. The public procurement regulatory framework should be aligned with and configured to the need to have the public procurement system that is effective, efficient and economical to the requisites of ensuring value for money procurement in the public services delivery system. Whereby, effective institutional framework for the envisaged public procurement system should qualify for the three pillars of institutions; that is: normative, regulative, and cultural-cognitive (Scott, 1994, 2004 and 2008). Normatively, Tanzania has not defined her public procurement modus operandi, national procurement values, norms and socio-economic aspirations, and guidelines and procedures (URT, NPPP, 2012 draft). One case respondent in the macro institutional policy level has argued that:

Effectiveness of the public procurement policy should be seen when it tries to align with the principle legislation. First, the policy should identify relevant policy issues to be dealt by the established policy. Second, the procurement legislation should provide for the governance and administration of the policy issues in ensuring that the activities found in the public procurement process and procedures are streamlined for value for money public sector procurements. Third, the public procurement legislation should be a mirror image of the public procurement policy framework.

Tanzania, however, has been faced by lack of public procurement policy since inception of the unified public procurement legal, institutional and systemic frameworks. Essentially, the policy issues that were identified and put into the first draft policy document (URT, NPPP, 2012 draft) are currently redundant due to emergence of new problems and/or policy related issues arising from the changes in political, economic, social, technological, ecological, and legal issues. It is by this scenario that, the entire proposed public procurement policy paper (URT, NPPP, 2012 draft) has been rendered redundant and/or obsolete altogether. Three interviewees from the micro, mezzo and macro institutional policy levels have observed that:

The delay of the public procurement policy development process has made the entire process out-dated. Here, the identified problems that made the viability of the policy issues are time barred and obsolete altogether. The effectiveness of the proposed policy paper whatsoever is obscured by the lapse of time. Whilst the principle public procurement legislation has been repealed twice (2004 and 2011 respectively) and amended once (2016); the first draft policy document (URT, NPPP, 2012 draft) is still within the shackles of the mezzo and macro institutional policy development levels waiting for the ill-defined, unqualified, and unstructured policy qualities that will not bring any effectiveness of the policy development.

\section{Conclusion}

Tanzania has no national public procurement policy framework. Despite the deliberate initiatives of the Government of Tanzania to establish the policy division office in the ministry responsible for public procurement to deal with national public procurement policy, yet and still; the proposed policy paper has been in the mezzo and macro institutional policy development levels. The policy development process has been halted since 2012. The public procurement policy development process in Tanzania has been faced by noticeable systemic 
challenges. These challenges, inter alia, were and still are: the neglected politics and lack of political willingness; the unrealistic policy process model; the failure to achieve the desired qualities of policy development and difficult in achieving the policy qualities and therefore failure to make progress; and the incoherent and incomplete institutional and structural changes that led to the emergence of new institutional and structural challenges.

Despite the systemic challenges facing Tanzania public procurement policy development process, there are positive prospects if at all the political system could use the envisaged systemic challenges to streamline the public policy development model. Once the Tanzania public policy development model is streamlined to capture the real world policy making phenomenon, the national public procurement policy dream will eventually be realised. Tanzania is in high need of the public procurement policy framework to ensure that its public sector procurements are governed, administered, controlled and executed by considering the principles of value for money. Tanzania needs effectiveness, efficient, economic, transparent and accountable public procurement system. The essence of ensuring effective, efficient and value for money public procurement system is the national public procurement policy framework. Therefore, Tanzania highly needs the national public procurement policy framework. The public policy development process needs revamping from where it was halted. The Government of Tanzania has socio-political and socio-economic obligations to resume the procurement policy development process within and across the mezzo and macro institutional levels within the public policy development framework. It is a matter of political will to stir up the public procurement policy development process. None can do it except the political elites and cadres in the Tanzania political system.

\section{Acknowledgements}

The author acknowledges to Mzumbe University (Mzumbe, Tanzania) that financed the research towards writing this academic paper. To Professor Shiv Kumar Tripathi of Mahatma Ghandi University, India (formerly professor of strategic business management at Mzumbe University - Dar es Salaam Campus College) who supervised the author in his $\mathrm{PhD}$ by research. To Dr Wilhelm Leonard of School of Public Administration and Management (Mzumbe University, Tanzania) who co-supervised the author. Lastly but not the least, to the case respondents in the micro, mezzo, and micro institutional policy levels in the Tanzania policy development framework whose anonymity is hereby maintained.

\section{References}

Alhojailan, M. I. (2012). Thematic analysis: A critical review of its process and evaluation. West East Journal of Social Sciences, Volume 1, Number 1. West East Institute.

Amenta, E. and Ramsey, K. M. (2010). Institutional theory. Chapter 2, in Leicht, K. T and Jenkins, J. (Eds.). Handbook of Politics: State and Society in Global Perspectives. Springer.

Caravella, R. K. D. (2009). U.S. federal government procurement: Organizational structure, process, and current issues. International handbook of public procurement, Khi V. Thai (ed.), 
Taylor \& Francis Group, LLC: USA.

Cassell, C. and Symon, G. (1994). Qualitative methods in organizational research: A practical guide. Sage Publication Ltd.

Easton, D. (1957). An Approach to the Analysis of Political Systems. World Politics, IX, pp. $383-400$

Easton, D. (1965). A systems analysis of political life. New York: Wiley.

Gordon, T. J. (2008). The Delphi Method. Futures Research Methodology - V3.0. The Millennium Project.

Hallsworth, M, Parker, S, and Rutter, J. (2011). Policy making in the real world: Evidence and analysis. Institute of Government. 2 Carlton Gardens, London SW1Y 5AA, UK.

Hsu, Chia-Chien and Sandford, B. A. (2007). The Delphi technique: Making sense of consensus. Practical Assessment, Research and Evaluation. Volume 12, Number 10, August 2007 (A peer-reviewed electronic journal).

Jahoda, M, M. Deutsch, and W. Cok (1958). Research methods in social relations. New York: The Dryden Press.

Krishnaswamy, K. N, A. I. Sivakumar and M. Mathirajan. (2009). Management research methodology: Integration of principles, methods and techniques. Dorling Kindersley (India) Private Ltd, New Delhi.

Obanda, W. P. (2010). Fighting corruption in tactical procurement. A PhD dissertation (mimeo). University of Twente: The Netherlands.

Polski, M. M. and Ostrom, E. (1999). An institutional framework for policy analysis and design. Workshop in Political Theory and Policy Analysis. Department of Political Science: Indiana University.

Ritchie, J and Lewis, J (Eds.). (2003). Qualitative research: A guide for social science students and researchers. SAGE Publications Ltd: London, UK.

Scott, W. R. (1994). Law and organizations. The Legalistic Organization, 3-18, Sim B. Sitkin and Robert J. Bies, eds. Newbury Park, CA: Sage.

Scott, W. R. (2004). Institutional theory. Encyclopaedia Theory. Thousand Oak, CA.

Scott, W. R. (2008). Institutions and organizations: Ideas and interests, $3^{\text {rd }}$ edition. Los Angeles: Sage.

Tukamuhabwa, B. (2012). Antecedents and consequences of public procurement non-compliance behaviour. In Journal of Economics and Behavioural Studies, Vol. 4, No. 1, pp. $34-46$.

United Nations' Publications. (1999). United Nations Commission on International Trade Law [UNCITRAL] Procurement Modal Law. NY, United States. 
URT. (1992). Procurement and Supply Management Study. Report by the Crown Agents submitted to the Ministry of Finance and Planning. Dar es Salaam, Tanzania.

URT. (1996). Tanzania Country Procurement Assessment Report 1996. Dar es Salaam: Tanzania.

URT. (2001). Public Procurement Act No. 3. Government Printer. Dar es Salaam, Tanzania.

URT. (2003). Tanzania Country Procurement Assessment Report 2003, Vol. 1, Dar es Salaam, Tanzania.

URT. (2004). Public Procurement Act No. 21. Government Printer. Dar es Salaam, Tanzania.

URT. (2006). Local Government Capital Development Grant [LGCDG] System: Legislation, Roles and Responsibilities for Local Governments. Prime Minister's Office Regional Administration and Local Government (PMO - RALG). Dodoma, Tanzania.

URT. (2007). Tanzania Country Procurement Assessment Report 2007. Dar es Salaam: Tanzania.

URT. (2011). Public Procurement Act No. 7. Government Printer. Dar es Salaam, Tanzania.

URT. (2012). The National Public Procurement Policy. Draft Policy Document. Ministry of Finance (MOF). Dar es Salaam, Tanzania.

URT. (2016). Public Procurement Act [Amendments] No. 5. Government Printer. Dar es Salaam, Tanzania.

Watermeyer, R.B. (2011). Regulating public procurement in Southern Africa through international and national standards. Paper presented at the Public Procurement Regulation in Africa Conference, 25 October 2011, Stellenbosch, South Africa.

Witten, I. H. and Frank, E. (2005). Data mining: Practical machine learning tools and techniques, $2^{\text {nd }}$ Edition. ELSEVIER: Morgan Kaufmann Publishers. San Francisco, CA 94111.

Wittig, W. A. (1999). Building value through procurement: A focus on Africa. Paper presented to the $9^{\text {th }}$ International Anti-Corruption Conference. [Online]. Available at www.legacy.transparency.org . Accessed on the $04^{\text {th }}$ of April, 2016.

Wittig, W.A. (2007). Public procurement and the development agenda. [Online]. Available at www.wto.org. Accessed on the $05^{\text {th }}$ January, 2015.

\section{Copyright Disclaimer}

Copyright for this article is retained by the author(s), with first publication rights granted to the journal.

This is an open-access article distributed under the terms and conditions of the Creative Commons Attribution license (http://creativecommons.org/licenses/by/3.0/). 